\title{
O Don Juan em Florbela Espanca
}

\author{
Sheila Katiane Staudt*
}

\begin{abstract}
Resumo: Este trabalho pretende identificar o "Donjuanismo" presente nos poemas de Florbela Espanca, observando de que forma esta característica aparece em seus versos juntamente com outras marcas recorrentes como, por exemplo, o erotismo, a desilusão amorosa e a constante busca pelo amor impossível, estabelecendo desta forma relações entre alguns de seus poemas. Primeiramente, faz-se necessário apresentar o mito de Don Juan a fim de que se entenda a origem desta nomenclatura, neste momento, utilizamos os textos $O$ mito literário de Don Juan, de Irlemar Chiampi e Antônio Moriana e $A$ sedução de D. Juan em comparações literárias $e$ métodos teóricos, de Dalma Nascimento. Recorremos também ao estudo de Patrícia Aragão intitulado $O$ Donjuanismo na poesia de Florbela Espanca: "Amar, amar e não amar ninguém !”, para esclarecer ainda mais esta questão.
\end{abstract}

Palavras-chave: Donjuanismo; desilusão amorosa; Florbela Espanca.

\begin{abstract}
This work aims at identifying Don Juanism in Florbela Espanca's poems and at observing how this characteristic is found in her sonnets along with other important themes, such as eroticism, love disillusion and the search for an impossible love, and thereby establishing connections among some of her poems. At first, we present the myth of Don Juan in order to understand the origins of the name, for which we make use of Irlemar Chiampi and Antônio Moriana's $O$ mito literário de Don Juan, and Dalma Nascimento's A sedução de D. Juan em comparações literárias e métodos teóricos. The studies by Patrícia Aragão were also used in this work in order to clarify how Don Juanism operates in Florbela Espanca's sonnets.
\end{abstract}

Keywords: Don Juanism; love disillusion; Florbela Espanca.

\section{Introdução}

No presente trabalho, pretendemos verificar nos poemas de Florbela Espanca uma característica peculiar em seus sonetos: o Donjuanismo. Primeiramente, faz-se necessário trazer o mito de Don Juan a fim de que se entenda a origem desta nomenclatura.

Por estar tão preso à figura masculina, o Donjuanismo parece, à primeira vista, impossível de ser encontrado em poemas feitos por uma mulher. No entanto, é preciso evidenciar da melhor maneira possível, como esta singular característica se apresenta nos versos da poeta Florbela Espanca.

Nossas reflexões são baseadas em estudos já realizados sobre a poesia desta poetisa. Entretanto, muitas outras partirão de impressões pessoais e leituras feitas por nós, já que

\footnotetext{
* Sheila Katiane Staudt é graduada em Letras pela UFRGS. Atualmente, cursa o mestrado em Literatura Brasileira na mesma Instituição.
} 
entendemos que é sempre possível ler um poema em uma nova perspectiva e assim acrescentar nuances à leitura desse, tendo em vista que cada sujeito é tocado diversamente por uma obra de arte.

\section{Mito de Don Juan}

A fim de compreender com clareza como a característica denominada "Donjuanismo" aparece nos versos da poeta Florbela Espanca, faz-se necessário esclarecer a origem do mito de Don Juan. A partir da abordagem feita por Chiampi e Moriana temos uma contextualização acerca das origens do mito, segundo eles

\footnotetext{
Antes que viesse a constituir um poderoso paradigma de sedução masculina, através da grande literatura, Don Juan freqüentava as lendas populares medievais, com outras designações: era o "don galán", ou o "mozo alocado" que gostava de ir à missa "para mirar las damas" [...] Com El Burlador de Sevilla y convidado de piedra (1630), Tirso de Molina dilata aquele elemento embrionário do penchant para as mulheres, [...] em um aristocrata provinciano espanhol que procura, no ato amoroso, a voluptuosidade de uma profanação. (CHIAMPI e MORIANA, 1987, p. 58-59)
}

Com isso, vemos que, em sua origem, o mito de Don Juan é fortemente relacionado com a figura masculina, possuindo as características de um conquistador de mulheres que não se interessa em manter apenas um relacionamento, mas que tem por objetivo colecionar várias conquistas amorosas ao longo de sua vida.

$\mathrm{Na}$ reflexão de Nascimento a respeito da figura de Don Juan, ela aponta inúmeras características atribuídas a este mito desde a publicação da obra de Molina (com o pseudônimo de Gabriel Tellez) até os nossos dias, ela diz:

D. Juan é analisado como ateu, hipócrita, onipotente, sádico, narcísico, metafísico, calculista, dionisíaco, maldito, sonhador do infinito, dilemático, maquiavélico, galante, pecador, revoltado, santo, revolucionário, fáustico, arrependido, ridículo, ... ou frágil menino. São epítetos vários para escamotear o "pathos" trágico que se incendeia no cerne mítico deste amador infinito e indiferenciado que se perde ou se acha no drama da carne e do espírito também, sempre deslocando o obscuro objeto de seu desejo. (NASCIMENTO, 1991, p.83)

Desta forma, é possível pensar sobre as diferentes e, também, relacionadas marcas que este Don Juan recebeu e continua recebendo ao longo da história, pois sendo um mito que desperta grande interesse na literatura mundial, está cercado de análises e estudos, e como afirmam Chiampi e Moriana "Don Juan é, certamente, o eterno condenado à significação e por isso mesmo transformou-se num mito." (CHIAMPI e MORIANA, 1987, p. 59).

Outra interpretação a respeito do mito de Don Juan encontra-se na opera buffa Don Giovanni de Mozart/Da Ponte. Segundo considerações de Chiampi e Moriana, esta ópera realizada nas vésperas da Revolução Francesa, “imprime ao personagem uma dimensão social 
e política assentada entre o prazer ("Vivan le femmine!Viva el buon vino!") e a rebeldia desafiante ("Viva la livertà!")." (CHIAMPI e MORIANA, 1987, p. 59). Nesta ópera foi criada a famosa cena onde o criado se refere às mil e três mulheres conquistadas por Don Juan na Espanha.

\section{O Don Juan nos versos de Florbela}

Após a descrição trazida a respeito do mito de Don Juan, torna-se viável a análise dos poemas de Florbela e a verificação do Donjuanismo em seus versos.

Cabe aqui elucidar que, ao referir os poemas de Florbela não falaremos do "eu lírico" que fala através dos seus versos mas, sim, seguiremos o estudo de José Régio, estudioso que afirma ser a obra de Florbela "a expressão poética de um caso humano", ou seja, tudo o que está dito em seus poemas são referências às suas próprias experiências verdadeiramente sentidas pela poeta durante sua vida; logo há uma ligação forte entre a vida e a obra da poeta como se tivéssemos um espelho da história de sua vida que se reflete em seus versos. Posto isso, toda vez que mencionarmos passagens dos sonetos de Florbela estaremos nos referindo ao sentimento da própria poeta que está imbricado em seus poemas.

Uma característica mencionada por Nascimento e relacionada diretamente com a figura de Don Juan é o narcisismo, característica esta facilmente observada nos poemas de Florbela, já que a poeta olha para si mesma em seus versos, fala de sua vida nos poemas, bem como de si própria, e isso pode ser evidenciado quando detectamos três de seus sonetos com os títulos $E u, E u$ e $S O U E U !$ A partir disso, podemos notar uma semelhança relevante entre Don Juan e a poeta em questão Florbela Espanca, pois sendo ambos narcisistas possuem esse traço que se torna destruidor ao longo de suas vidas, no instante em que, ao enxergarem somente a si mesmos, deixam de valorizar o outro e tudo mais que o cercam para enfatizarem apenas o seu próprio "eu” e isso traz malefícios durante a trajetória dos mesmos.

A fim de identificar o Don Juan existente em Florbela, serão apresentados alguns versos de seus poemas para que seja realizada a devida análise e reflexão desta singular característica.

No poema intitulado "Prince Charmant..." dedicado a Raul Proença, é possível observar perfeitamente o "Donjuanismo" que existe nesta poeta ao lermos: "Em toda nossa vida anda a quimera/ Tecendo em frágeis dedos frágeis rendas.../ - Nunca se encontra Aquele que se espera...”(ESPANCA, 1980, p.88). A busca incessante por outro alguém diferente do anterior encontrado é marca forte do mito de Don Juan e fica evidente quando 
vemos o último verso deste poema onde há a afirmação literal de Florbela e até mesmo uma aceitação de seu fado, ao dizer que "Nunca se encontra Aquele que se espera..."(ESPANCA, 1980, p.88). Notamos que a referência ao ser desejado encontra-se grafado com inicial maiúscula e disso depreendemos que não se trata de um homem (no caso da poeta) qualquer, aleatório, mas sim de um Alguém específico, determinado, que nunca será encontrado segundo ela. Contudo, ao compararmos com o mito de Don Juan percebemos que encontrar Alguém em especial não é o seu principal objetivo, mas o contrário, para ele o que vale são as diferentes conquistas que terá pela frente, não se prendendo a uma apenas, pois a quantidade tem importância maior que a grandeza de seus amores.

Em outro poema de Florbela denominado "Loucura", fica também evidente o número de relacionamentos experienciados pela poeta quando lemos: "Passa em tropel febril a cavalgada / Das paixões e loucuras triunfantes! / Rasgam-se as sedas, quebram-se os diamantes! / Não tenho nada, Deus, não tenho nada!...” (ESPANCA, 1980, p. 200), essa marca pode ser aproximada ao Don Juan que permeia os sonetos da poeta, já que ela aproxima as suas vivências amorosas a uma "cavalgada das paixões" por ela vivida, é como se pudéssemos visualizar seus relacionamentos como passageiros, já que vêm de forma arrebatadora através da imagem de um tropel de cavalos e que, por sua característica agressiva e inconstante, nada restará no final dessas experiências vividas tão abruptamente, como ela diz no último verso: "Não tenho nada, Deus, não tenho nada!...”(ESPANCA, 1980, p.200), sendo muito semelhantes aos casos passageiros vividos por Don Juan em suas andanças.

Ao analisarmos o poema "Alma perdida", captamos aquilo que pode ser a resposta a todo o sofrimento da poeta e sua aproximação com o mito de Don Juan. Nos versos: "Tu és, talvez, um sonho, que passou, / Que se fundiu na Dor, suavemente .../ Talvez sejas a alma, alma doente / Dalguém que quis amar e nunca amou!" (ESPANCA, 1980, p.57), ao fazer comparações entre um rouxinol e sua própria alma, percebemos a conclusão a que chega a poeta: ela nunca amou e sempre quis fazê-lo. Temos aqui uma possível resposta à busca incessante de Florbela por um amor verdadeiro, o qual ela sabe e tem consciência, que nunca irá encontrar (explícito no poema "Prince Charmant..." citado anteriormente), resposta esta que poderia ser nunca ter amado de verdade nenhum de seus amores no passado, ou seja, não conhecer de verdade o que é um amor em toda sua plenitude, podendo ser isto que faz a poeta viver eternamente à procura de um ser amado e possuir tantos romances durante a sua vida apenas com a finalidade de algum dia descobrir o que é o amor verdadeiro e não mais viver aventuras amorosas que lhe trazem mágoa e sofrimento. 
Depois desta análise, poderíamos dizer que Don Juan, também estaria tentando saber o que é amar de verdade, embora não esteja consciente disso, e que para finalmente encontrar o seu verdadeiro amor, foram necessárias inúmeras conquistas anteriores. A partir disso, é compreensível então, em ambos os casos - em Don Juan e em Florbela - a questão da constante busca pelo amor, busca esta empreitada por meio de diversas experiências amorosas, pois entendemos ser difícil a tarefa de amar de verdade, de saber se aquele novo amor será o último e não mais um caso que deixará saudades, de distinguir qual o sentimento que temos por alguém, já que possuímos tanta sensibilidade dentro de nós. Enfim, é árduo o trabalho de certificarmo-nos acerca de nossos próprios sentimentos e, muitas vezes, nosso instinto age por nós e, enquanto isso, "encontramo-nos e nos perdemos" ao mesmo tempo, mas sempre buscando o melhor caminho.

A partir do estudo de Patrícia Aragão, evidenciamos outra resposta para esta busca pelo amor encontrada nos versos de Florbela e denominada "Donjuanismo"

Saber se perder para se encontrar - "Que me saiba perder... pra me encontrar..." - pode significar saber se desprender de um amor que partiu para estar aberta a um novo amor que surgirá, uma vez que, se ele se foi, não há nada a ser feito: recordar ou esquecer? É indiferente, pois nada poderá ser feito e não porque o ser deixou de ser amado: partiu e não voltará. Quando o Outro não corresponde ao amor do $\mathrm{Eu}$, não há o que mude seus sentimentos. (ARAGÃO, 2004, p.15)

Neste trecho, Aragão apresenta uma interpretação mais racional acerca da questão de se esquecer um amor após a perda do mesmo. Ela nos diz que nada pode ser feito ou alterado em relação aos sentimentos do Outro e, com isso, resta esquecê-lo ou, até mesmo, relembrálo, já que neste ponto torna-se indiferente.

O melhor poema para identificar o Don Juan nos versos da poeta é, segundo Aragão, o poema intitulado "Amar", onde aparece quase que uma confissão de Florbela nos seus primeiros versos: "Eu quero amar, amar perdidamente! / Amar só por amar: Aqui...Além.../ Mais Este e Aquele, o Outro e toda a gente... Amar! Amar! E não amar ninguém!". É possível identificar o desejo profundo em que vive a poeta ao querer amar, amar muito, amar intensamente, às vezes, só por amar, e no fim disso tudo, não amar ninguém! Retomamos a reflexão feita anteriormente acerca do poema "Alma Perdida" no qual também há outra confissão de Florbela ao revelar que nunca tinha amado de verdade e, assim, fica evidente a sua semelhança com Don Juan, já que ambos vivem suas vidas nesta constante busca pelo amor, vivenciando diferentes "falsos-amores" em suas trajetórias e fazendo uso do erotismo para conquistarem e atraírem esses amores.

Aragão em seu estudo evidencia esta outra característica marcante nos poemas de Florbela - o erotismo - ao dizer que "a sensualidade dos versos de Bela encanta e seduz os 
sentimentos de quem lê e torna-se impossível não mencionar seu caráter erótico.”(ARAGÃO, 2004, p.10). Podemos perceber essa marca no poema intitulado "O Meu Desejo": "Minha boca tem fome só da tua! / Meus olhos têm sede só dos teus!", onde é evidente a sensualidade e o erotismo em suas palavras ao fazer um juramento a um "amor"(ou falso-amor) de que seus olhos são só para ele, bem como a sua boca é fiel só à boca dele, mas a poeta faz essa promessa com expressões carregadas de desejo e paixão carnais que dá o caráter erótico ao poema.

\section{Considerações finais}

Com o estudo realizado, foi possível visualizar de que maneira o "Donjuanismo" aparece nos poemas de Florbela Espanca. As aproximações feitas entre o mito e a poeta, como, por exemplo, a característica narcísica de ambos ajudaram a verificar a presença do Don Juan nos versos de Florbela.

A ligação de outras características contidas em seus poemas com o "Donjuanismo" revelou-se coerente, na medida em que, o erotismo é usado como instrumento para as conquistas amorosas tanto de Don Juan, quanto de Florbela e, a desilusão amorosa torna-se clara ao vermos que a busca pelo amor está em constante movimento, pois no instante em que se perde o ser amado por qualquer que seja o motivo, há em seguida a demanda por outro amor que possa ocupar aquele lugar agora desabitado.

Realizar este trabalho é uma das formas de sentir a poesia em toda a sua plenitude, pois através do diálogo com o poema pode-se obter inúmeras interpretações, já que cada pessoa tem emoções e sentimentos próprios que a distinguem em meio aos outros e, é isso que faz da obra de arte poética um diferencial, ao despertar inúmeras sensações e significados em diferentes leitores, torna-a possuidora de um raro poder: de não nos deixar indiferentes mediante a leitura de um poema, algo sempre nos é comunicado, impreterivelmente.

\section{Referências}

ARAGÃO, Patrícia. O Donjuanismo na poesia de Florbela Espanca: "Amar, amar e não amar ninguém!", Revista Agulha, 2004. Disponível em: http://www.revista.agulha.nom.br/monografiapatriciaaragao.pdf . Acesso em julho 2007.

CHIAMPI, Irlemar e MORIANA, Antonio G. O mito literário de Don Juan. In: SCHULER, D.; GOETTENS, M. B. Mito ontem e hoje. Porto Alegre: Ed. da Universidade/UFRGS, 1990. 
ESPANCA, Florbela. Sonetos Completos. Edição com estudo crítico de José Régio. Portugal: Bertrand,/Amadora 1981.

Sonetos. Introdução de Maria da Graça Orge Martins. Biblioteca Ulisséia de autores portugueses. 1990.

GONÇALVES, Maria M. T. et al. Homenagem à Florbela Espanca. In: Cadernos de Teoria e Crítica Literária. n.15, Araraquara: UNESP, 1988. 120 p.

NASCIMENTO, Dalma. A sedução de D. Juan em comparações literárias e métodos teóricos. In: ANAIS ANPOLL: V Encontro Nacional da ANPOLL. Porto Alegre: ANPOLL, 1991. 939 p. 2. v. 